\title{
¿Qué deja el conservadurismo neoliberal? \\ Resquebrajamiento de los lazos sociales y algunos desafíos de la política socio-laboral
}

\section{Estela Grassi}

Doctora en Ciencias Antropológicas

Investigadora Instituto de Investigación

Gino Germani

Correo: estelagrassi@gmail.com 


\section{Presentación $^{1}$}

El proceso eleccionario de octubre de 2019 transparentó -aún más, si fuera posible- la ideología que se apropió de una parte importante del modo de pensar y percibir a la sociedad y a los congéneres "no privilegiados", que en 2015 había permitido la llegada de un gobierno (la Alianza Cambiemos) que se propuso el objetivo de desmantelar las instituciones de protección social de base solidaria, sostenidas en derechos colectivos ${ }^{2}$. Si la resistencia popular, expresada en constantes movilizaciones ${ }^{3}$, impidió que tal objetivo se cumpliera a cabalidad, no alcanzó para frenar la intervención en el acceso a otros bienes y servicios de consumo colectivo (la energía, el agua, el transporte, por ejemplo) cuya total mercantilización por la eliminación indiscriminada de subsidios y la fijación de las tarifas a valores dolarizados de mercado, incidió en la insatisfacción de necesidades básicas de los sectores populares y, en general, en las condiciones de vida de las clases medias y bajas.

En el presente artículo me refiero, en primer lugar, al resquebrajamiento de los lazos sociales que produjeron las políticas cambiemistas orientadas por el neoliberalismo entre 2015 y 2019, al afectar, además de aquellas políticas sociales, las condiciones del empleo y,

\footnotetext{
1 Escribí ese artículo mientras transcurre la transición del gobierno de Mauricio Macri al de Alberto Fernández, quien fue electo el 27 de octubre y asumirá el 10 de diciembre de este año 2019. También, mientras los chilenos reaccionan contra los "privilegios", según reconoció la propia esposa del Presidente Piñera, hasta obligarlo a decidirse a proponer la reforma de la Constitución que pergeñara la dictadura de A. Pinochet. Y termino cuando se produjo un golpe al Estado plurinacional de Bolivia, que destituyó al presidente Evo Morales. Es decir, en medio de una enorme convulsión política, que por más de un momento me desvió de mis objetivos, lo que seguramente se notará en el texto final.

2 Con excepción de la Asignación Universal por Hijo (AUH) que, incluso, fue ampliada.

3 Las movilizaciones más masivas se produjeron en diciembre de 2017, contra los cambios introducidos en la fórmula de cálculo de los haberes previsionales, antesala de una reforma del sistema que no llegó a concretarse. Estas fueron duramente reprimidas (https://www.cronista.com/economiapolitica/ Incidentes-y-tension-en-la-protesta-en-el-Congreso-contra-la-reforma-previsional-20171213-0111. $\mathrm{html).} \mathrm{La} \mathrm{misma} \mathrm{violencia} \mathrm{de} \mathrm{las} \mathrm{fuerzas} \mathrm{de} \mathrm{seguridad} \mathrm{se} \mathrm{puso} \mathrm{en} \mathrm{práctica} \mathrm{durante} \mathrm{las} \mathrm{movilizaciones}$ convocadas por la familia y acompañadas por los organismos de derechos humanos por la aparición con vida de Santiago Maldonado, en septiembre de ese mismo año (https://www.pagina12.com. ar/66200-el-pais-marcha-por-santiago-maldonado). La CGT realizó cuatro paros generales (https:// www.infobae.com/politica/2018/09/25/la-cgt-encabeza-el-cuarto-paro-general-contra-el-gobiernode-mauricio-macri/). Y los maestros y trabajadores estatales se mantuvieron movilizados (https:// www.perfil.com/noticias/sociedad/docentes-realizan-un-paro-y-marchan-en-la-zona-de-congreso. $\mathrm{phtml} \quad$ (https://www.perfil.com/noticias/politica/paro-y-movilizacion-de-docentes-judiciales-ymedicos-bonaerenses.phtml). Además, durante todo el período se registraron innumerables protestas de los movimientos sociales y de trabajadores de diversos gremios.
} 
por lo tanto, la integración por el trabajo; y al naturalizar los privilegios de clase, desde los cuales se impone una mirada individualista y meritocrática aplicable a los sectores más desprovistos.

Dado el cambio de escenario político y de gobierno a partir de diciembre de este año 2019, planteo algunas situaciones urgentes de las que deberá hacerse cargo la política social del presidente Alberto Fernández, así como de cuestiones que deberían problematizarse e instalarse en el debate público, desde algunas referidas al trabajo, como aquellas necesarias para desmontar los prejuicios y la discriminación social que ponen en riesgo la vida social.

\section{El resquebrajamiento de los lazos sociales}

Han cumplido un siglo largo las ciencias sociales modernas nacidas con la obra de Emile Durkheim, principalmente con La división del Trabajo Social y su caracterización de la "solidaridad orgánica" que da lugar a un sistema de deberes y derechos para asegurar el concurso pacífico y regular de las funciones divididas en interés de la propia sociedad, ${ }^{4}$ cuya trama es condición de la existencia del individuo capaz de autovalerse y no a la inversa. Un poco menos de años tiene La gran transformación (1944) sobre Los orígenes politicos y económicos de nuestro tiempo (tal el subtítulo), la monumental investigación histórica de Karl Polanyi, donde muestra cómo la creencia impuesta por el liberalismo de mercado, que llevó a organizar la economía global y subordinar a la sociedad a sus designios, condujo al colapso económico tanto como a la destrucción de la urdimbre social. Sólo estas dos referencias deberían ser suficientes para no tener que recordar que fue la complejización de las sociedades capitalistas y las propias necesidades de la producción y expansión del capital lo que hizo necesario la ampliación de las funciones e intervenciones del Estado, porque la fuerza de trabajo y la paz social necesarias para la

4 "La división del trabajo no coloca frente a frente a individuos -dice Durkheim (1995:477-78)- sino a funciones sociales... y es la sociedad la que se halla interesada, pues...su existencia depende de eso y tanto más estrechamente cuanto más divididas se encuentren aquellas” (1995:477-78). 
¿Qué deja el conservadurismo neoliberal?

Resquebrajamiento de los lazos sociales y algunos desafíos de la política socio-laboral

producción no son condiciones naturales ni se derivan del mercado, sino de su organización política. En esos procesos se inscribe el desarrollo, no sin conflictos y disputas por su conveniencia y necesidad, de las estructuras institucionales (los sistemas públicos de protección y asistencia social y los equipamientos colectivos, en general) que sostienen la vida de las personas más allá de las redes cercanas (la familia o la comunidad inmediata). Esas necesidades "del capital" las sistematizó Christian Topalov, en La urbanización capitalista (1979) y Robert Castel dejó una producción ineludible al respecto, empezando por La metamorfosis de la cuestión social (1995).

Sin embargo, contra toda evidencia histórica, esos entramados institucionales son el blanco por excelencia del encono neoliberal y de la teoría económica que deja fuera de su objeto a aquello que le da existencia: la sociedad y los sujetos cuyas prácticas la reproducen. La obligación, la disciplina y las capacidades para trabajar no emanan de la voluntad de individuos más o menos dispuestos o perezosos, sino que se constituyen como configuraciones socio-políticas y por intervenciones e instituciones en las que los sujetos se hallan (nos hallamos) inscriptos y que literalmente sostienen su existencia y hacen posible o limitan el desarrollo de las capacidades, los talentos y los méritos, que son siempre potenciales.

Las políticas sociales conforman una parte de esa institucionalidad y son medulares en la determinación de las condiciones de la vida colectiva, pues son parte del andamiaje institucional estatal (político) que soporta la vida social, el ser individuo y la posibilidad de participar y autovalerse.

Sin embargo, no ha perdido vigencia el supuesto de la superación individual como única posibilidad legítima de sobrevivir y pertenecer de las personas y la desestimación de los sistemas públicos para la reproducción, mientras se exige mayor control represivo del Estado o se condiciona "la ayuda" a la prueba del merecimiento. La época trae, además, un ingrediente novedoso cual es el re-encantamiento del mundo con el que comulga buena parte de las bases sociales de los agrupamientos políticos que, como Cambiemos en nuestro país, ponen al Estado enteramente al servicio del mercado y de intereses 
privados. La voluntad del mercado y la voluntad de un dios arbitrario se conjugan: ambos exigen la entrega de los individuos y reparten premios y castigos a merecedores o culpables. En la región ${ }^{5}$, esta conjunción constituye, desde hace décadas, la ofensiva político-cultural (Pulser, 2019) de un neoliberalismo profundamente conservador, capaz de capturar el sentido común de amplias capas sociales por medio de nuevas formas de penetración y acción cultural. Estas van desde la proliferación de nuevas iglesias evangélicas cuyos dirigentes tienen militancia e inserción política, pasando por las cosmovisiones new age y naturalistas del mundo (Papalini y Echavarría, 2016), hasta la circulación de noticias falsas por las redes sociales y los medios de comunicación, que llevan al desprecio por la palabra de "los políticos” y al desinterés por la argumentación política. Y también en personajes y en el contenido y forma de ciertos discursos políticos mesiánicos, como los que en nuestro país ejemplifican la diputada Elisa Carrió y su par Alfredo Olmedo, ambos integrantes de la Alianza PRO-Cambiemos.

Precisamente, estas organizaciones políticas son parte de esa movida cultural, por el uso de las redes, la circulación de noticias falsas y los estilos de presentación de sus dirigentes, que asumieron las formas de actuación de aquellos predicadores y sus celebraciones festivas, contrarias a los actos políticos de masas. Después de la ocurrencia de las sucesivas crisis económicas, referidas por medio de las más diversas metáforas por el Presidente, principalmente desde 2018 cuando comenzó la mayor escalada del valor del dólar, se terminó el crédito internacional y el gobierno recurrió al FMI y se puso la economía bajo su tutela (Grassi, 2018) volvieron los rostros adustos de

5 Corregía este documento cuando se produjo el derrocamiento de Evo Morales en Bolivia y la autoproclamación de una presidenta, llevada a ese lugar por un sector de la sociedad boliviana blanca, conducido por el "Macho Camacho", un personaje que se propone como un restaurador de la fe: "Nunca más volverá la Pachamama. Bolivia es para Cristo", dijo (Revista Noticias, 11-11-2019). Hijo de una familia empresaria rica de Santa Cruz, se presentó con una enorme Biblia en el Palacio Quemado, que sostenía junto al grupo que proclamaba a la presidenta de facto. Esta, que también sostenía otro ejemplar del libro sagrado del cristianismo, coreaba "sí, se pudo", la consigna que instaló en nuestro país Mauricio Macri. Las fotografías de la asunción que circulan por los medios y redes sociales, eximen de más observaciones al respecto, pero alertan acerca del enorme peligro que representan los grupos religiosos fundamentalistas (la Iglesia Universal, por ejemplo) para la democracia en el continente (La Nación, 12-11-2019). 
sus dirigentes, pero no el recurso a la argumentación fundada para explicarlas.

\section{La mirada de los otros}

Casi concluido el mandato de Mauricio Macri y frente a las elecciones presidenciales, finalmente se hizo patente el conservadurismo ideológico de sus bases sociales y se transparentaron los prejuicios clasistas que, a su vez, explican la desconsideración de las consecuencias sociales de las medidas políticas asumidas a lo largo de sus años de gobierno. Un corto período durante el que se volvió a profundizar el resquebrajamiento del tejido y los lazos sociales por la incapacidad de reconocimiento de los "otros" (pobres o empobrecidos) y de asumir sus sufrimientos; y por la disociación del trabajo respecto del sujeto, con idéntica falta de empatía.

Precisamente, el contexto de las elecciones presidenciales de este 2019 fue un campo propicio para exabruptos y discursos que son la manifestación de aquella insensibilidad e incluso, de una deliberada actitud de discriminación y rechazo hacia la parte de la población más desprovista de recursos. La ajenidad respecto de las necesidades y sufrimientos de quienes se hallan en las peores condiciones de vida se hizo transparente al final, a través de los exabruptos de funcionarias y militantes cambiemistas tras la derrota en las elecciones del 27 de octubre, que no merecieron ningún llamado de atención pública por parte del Presidente, ni de autoridad alguna. ${ }^{6}$ Él mismo fue despectivo con los votantes opositores luego de conocerse los resultados de las elecciones Primarias Abiertas, Simultáneas y Obligatorias (PASO) cuando recriminó a los votantes por la nueva devaluación del peso con posterioridad a las $\mathrm{PASO}^{7}$.

6 Tras la derrota de Cambiemos en las elecciones de octubre, una legisladora oficialista compartió un whatsapp (reproducido por otra funcionaria) en el que se refiere a los electores como "monos a los que sólo hay que darles bananas", entre otras consideraciones igualmente degradantes. En la misma ocasión, circuló un twitter con la fotografía de un joven trabajador, que cumplía su función como autoridad de mesa en la localidad bonaerense de Moreno, atravesada con una leyenda que aconsejaba "si vas a votar, no lleves nada de valor" (Clarín, 29-10-2019; Perfil, 29-10-2019).

7 "Esto es sólo una muestra de lo que puede pasar. El mundo ve esto como el fin de la Argentina” (La 
Por cierto, la discriminación y estos prejuicios no hicieron su aparición en este momento, ni siquiera en los últimos cuatro años del gobierno neoliberal sino que, como mostramos en investigaciones previas (Grassi y Hintze, 2018) Cambiemos fue la opción elegida porque ofrecía control, orden y libremercado y ayuda (no derechos) sólo para quienes demostraran merecerla. La política los exacerbó por sus discursos y por las consecuencias socio-económicas, que ampliaron las tramas de la desigualdad y dañaron más la urdimbre de la sociedad.

Así, las intervenciones, interpretaciones o justificaciones en boca de dirigentes y funcionarios de gobierno, a quienes les cabe la responsabilidad por ser o hablar por el Estado, manifestaron natural y espontáneamente ese desapego e indolencia para con "los otros", sin que ello suponga la menor incorrección política. Que el ex ministro de Educación se vanaglorie porque "todos los días (hay) un pibe más preso" (ver infra) es, quizás, la expresión más cabal de esta indiferencia que ofrece los fundamentos e inspira los objetivos de una política de expulsión de quienes son los "elementos indeseados" de y para un delimitado universo de "gentes" autoerigida en esencia de la nación y que solo al final incluyó a "la clase media" que el Presidente dijo haber escuchado ${ }^{8}$ después de que se anticipara en las PASO su derrota como candidato para un segundo mandato presidencial. La composición social uniforme de los actos de campaña posteriores, durante la llamada "marcha del millón", y el cotillón igualmente uniforme, compuesto sólo de banderas argentinas -ya sin los globos amarillos propios de la estética festiva del $\mathrm{PRO}-$, da cuenta de la apropiación del símbolo patrio (la bandera) por una parcialidad política (PROCambiemos) que se presenta y representa como la totalidad de la nación?.

Nación, 12-08-2019).

8 A esos sectores el empresario Grobocopatel identificó como "la gente común" cuyo vuelco a la compra de dólares habría hecho necesario imponer restricciones ante la pérdida de reservas en el Banco Central. Se trataría, según dijo, "no necesariamente de empresas o personas ricas, sino también de gente común” (Página/12, 30-10-2019).

9 Después de conocerse los resultados de las elecciones Primarias Abiertas, Simultáneas y Obligatorias (PASO), que adelantaban su derrota en la primera vuelta electoral, Macri organizó distintas marchas por el país tras la consigna "Sí, se puede" (revertir ese resultado). No funcionó, pero logró actos multitudinarios con una alta composición de adultos y mujeres portando banderas argentinas (Infobae, 
La promesa fantasiosa de "pobreza cero" cuando en 2015 Macri aún era candidato fue, apenas, una estrategia de campaña que culminó, al final de su mandato, en una emergencia alimentaria desatendida y en las denuncias de situaciones de hambre que afectan principalmente a niñes. Para el primer semestre de 2019 la pobreza comprendía al $25,4 \%$ de los hogares y al 35,4\% de las personas. La situación es más dramática si se atiende a la población de entre 0-14 años. En este caso, el 52,6\% son pobres y un 13,1\% de ellos viven en la indigencia.

Son datos del INDEC de $2019-\mathrm{a}^{10}$ que algunos dirigentes insisten en desconsiderar. Tampoco parece que puedan imaginar su propia responsabilidad política por el futuro que espera a estas generaciones, porque en el transcurso entre aquella promesa y estos resultados, el control, el merecimiento y la ayuda fueron los ordenadores de la política de asistencia social, que se combinaba con la política de seguridad hostil con los más pobres, especialmente con las y los jóvenes (Ayos y Jack, 2018).

"Lo hacemos por vos, que cumplís", rezaba la propaganda oficial cuando, lejos de revisar las debilidades del Plan de Becas Progresar para alcanzar el objetivo de la integración al sistema educativo, se limitaba al control y expulsión de los incumplidores: el plan se mantenía reconvertido en premio al esfuerzo individual contra aquel objetivo. La misma dirección hacia la individualización de la ayuda adquirieron los programas de transferencias por contraprestación laboral, descuidándose a las cooperativas (Hintze, 2018).

Junto al retorno de la ayuda como política social, volvía un componente clásico de la asistencia a los pobres, cual es la desconfianza y la preocupación por el abuso. Una preocupación coincidente con

19-10-2019). Como en otras ocasiones, no se privaban de manifestar opiniones prejuiciosas. Por su parte, el candidato elevaba los ojos al cielo, cual predicador, mientras planteaba preguntas capciosas (si la honestidad es importante, si la educación y el trabajo son el camino para progresar, si la Justicia tiene que ser independiente, si hay que combatir a los narcos y las mafias) a las que, casi en trance, los "fieles" repetían ¡"Siii"! (Infobae, 19-10-2019). Ocurridas las elecciones definitivas y conocido el escrutinio que daba ganador a Alberto Fernández, los exabruptos circularon por las redes. Uno de los más extremos provino de una candidata del PRO y fue reproducido por una funcionaria, "A los monos sólo hay que darles bananas” fue lo más suave que twiteó la dirigente, refiriéndose a los votantes opositores (Clarín, 29-10-2019).

10 falta nota 
demandas que se expresaban en el espacio de lo público, por mayor control para detectar "verdaderas necesidades" y con una soterrada culpabilización de las barriadas populares por la inseguridad en la sociedad. Las víctimas de la desprotección se volvían, así, las clases peligrosas, una escoria que hay que separar. Y con ello, se rompían las últimas resistencias al peligro que puede representar el propio Estado. La política de seguridad se propuso como la lucha contra el narcotráfico, pero dio pie a la intervención policial con mayor rudeza e irrespeto de los derechos de estas poblaciones (Sabarots, 2018).

"El camino que hemos emprendido todos los días tiene un metro más de asfalto, una sala más, un pibe más que está preso", dijo Esteban Bullrich, cuando renunció al cargo de ministro de Educación de la Nación para proponerse como senador nacional por la provincia de Buenos Aires, cargo al que accedió con la mayoría de los votos y ejerce desde octubre de 2017 (La Nación, 08-08-2017).

\section{El trabajo no es lo que parece}

Si el egoísmo es un rasgo de la cultura neoliberal, la enajenación del trabajo respecto de quien lo hace, está en el corazón de su proyecto económico. Los "problemas de empleo" fueron tratados apenas como una variable de ajuste para mejorar la productividad de las empresas o asegurar las inversiones, en el mismo plano que cualquier otra variable económica.

Contar con trabajo, pero no lidiar con trabajadores (menos aún, organizados) llevando al máximo la mercantilización y la privatización de su reproducción, es un ideal del capital reforzado con el extraordinario desarrollo tecnológico y la automatización de las últimas décadas. Un ideal desde cuya lógica no puede esperarse el cuidado de la sociedad.

Las primeras medidas referidas al trabajo que vislumbraban el descuido del sujeto, tuvieron como protagonista al propio Macri, cuando a principios de 2016 vetó una ley del Congreso de la Nación por la que se buscaba frenar los despidos como medida preventiva frente a la posible agudización del problema social del desempleo. Después, el 
Congreso daría su apoyo al Ejecutivo, al aprobar la modificación del régimen complementario de la ley 24.557 sobre riesgos del trabajo, que impuso más trabazones para el reconocimiento de enfermedades y accidentes laborales. Y pronto los problemas de empleo sirvieron para justificar la proposición de una reforma laboral que, según el diario La Nación, hallaba inspiración en "algunos de los atributos presentes en la reforma laboral que fue aprobada en Brasil”, tales como la reducción del preaviso cuando se cancela el contrato, la desvinculación del monto de las indemnizaciones respecto del salario o la posibilidad de contratar empleados en forma intermitente (La Nación, 16-09-2017) ${ }^{11}$.

En lo proyectado localmente estaba el objetivo de avanzar en la facilitación y abaratamiento de los despidos, la rebaja de aportes patronales a la seguridad social, la eliminación de la responsabilidad compartida cuando se tratara de tareas tercerizadas y la incorporación de algunas modalidades de contratación a término, principalmente en lo que se refiere al empleo juvenil. En general, en la propuesta resuenan los ecos de las reformas de la década de 1990, aunque presentadas con un lenguaje remozado, como la "lucha contra la evasión".

En el mismo encuadre ideológico que inspiraba las propuestas de reforma, el Ministerio de Trabajo, Empleo y Seguridad Social abandonó su papel en la mediación de la relación laboral y la protección de los trabajadores (Grassi, 2018:164), hasta su desjerarquización en 2018, cuando pasó a ser una Secretaría del Ministerio de la Producción.

Al gobierno de Cambiemos no le alcanzó el tiempo y la fuerza política para lograr imponer una reforma laboral integral que retrotraiga los derechos resguardados por el contrato de trabajo, en la que el gobierno insistió, aunque igualmente ya la mitad de la fuerza laboral estaba fuera de sus alcances, empleándose informalmente, por cuenta propia o subsistiendo en los márgenes de la economía (ODSA, 2019).

11 Según la misma nota, la reforma en ese país "también relajó las condiciones mínimas de salubridad en las condiciones del ambiente de trabajo para las embarazadas". 
Ese sector no constituyó un problema para la política laboral, apenas preocupada por "la evasión".

En el último año de mandato cambiemista, la desocupación volvió a los dos dígitos (10,1\%). Además, 17,5\% de los ocupados eran, a su vez, demandantes de empleo, lo que expresa insuficiencia y/o malestar. La situación es peor para la población joven: 18,5\% de los varones de 14 a 29 años estaba desempleado en el primer trimestre de 2019, y el $23,1 \%$ de las mujeres de esa edad se hallaba en la misma situación (INDEC, 2019-b).

Igualmente, el gobierno mostró hasta el final la desconsideración que la vida humana le merece al mercado. Muy cerca de finalizar su mandato, el presidente Macri firmó un decreto de Necesidad y Urgencia 669/2019 disponiendo la reducción de las indemnizaciones por accidentes de trabajo, que tiene como justificación "las condiciones económicas y financieras recientes” (La Nación, 03-09-2019). Además de que esas condiciones son resultado de los comportamientos especulativos habilitados por la política del gobierno, la medida fue tomada a menos de un mes de la ocurrencia de un derrumbe en las obras de ampliación del Aeropuerto Internacional de Ezeiza, en el que falleció un obrero y otros trece resultaron heridos (Infobae, 03-09-2019).

El DNU y la oportunidad en la que se tomó esta decisión no son más que otra expresión de una ideología que ignora la vida social. También en este caso la ideología se transparenta en los propios discursos: "El secretario de Empleo y ex CEO del grupo Techint, Miguel Ángel Ponte, opinó que incorporar o despedir personal debería ser para las empresas natural como "comer o descomer". En diálogo con Radio con Vos (...) sostuvo que "la posibilidad de entrar y salir del mercado laboral hace a su esencia; es como comer y descomer" (Perfil, 09-01-2017).

La metáfora biologista del funcionario expone gráficamente aquello que la teoría se esfuerza en explicar en términos de costo de los factores. Desde el punto de vista de la producción, el trabajo es energía (fuerza de trabajo), uno de esos factores, como el capital o la 
tecnología. Desde ese estricto punto de vista, lo que no se usa, es desechable porque no produce.

A ese ideal se prestan bien las nuevas formas de empleo por plataformas: permiten individualizar el intercambio con un particular que dispone y pone al servicio de la prestación todos los medios de trabajo, sin ningún lazo de dependencia, pero subordinado a la demanda que canaliza la empresa. Si la política de regulaciones del gobierno del Frente para la Victoria había intentado proteger incluso a aquellos segregados del mercado laboral, aunque no lograra su integración formal al mismo ${ }^{12}$, la política del gobierno de Cambiemos, que comulga con la utopía de un capitalismo sin asalariados (más precisamente, sin trabajadores en relación de dependencia y atomizados), facilitó las cosas a las nuevas formas de empleo en empresas de servicio (Glovo o Rappi, Pedido Ya, entre las más visibles y con mayores riesgos, pero también los servicios que se prestan desde el domicilio por una conexión remota) sin protecciones ni más regulaciones que las del contrato entre privados (Unzué y Chávez Molina, 2019). El desempleo entre los y las jóvenes, hizo su parte.

El trabajo es un costo para el capital aunque esté implicada la humanidad de quienes lo hacen y de quienes quedan afuera de esa posibilidad. Pero una buena parte de la reproducción fue socializada a través de las políticas sociales, los consumos colectivos y demás intervenciones del Estado (la infraestructura urbana y de transporte, por ejemplo), que también hacen posible la disponibilidad de fuerza de trabajo (trabajadores en sus distintos estamentos) en condiciones, capacitada y disciplinada para trabajar. De ahí que, entre la socialización de la reproducción y la acumulación privada existe una relación de contradicción y de necesidad, simultáneamente, porque tratándose de las condiciones generales de la producción y de la reproducción, aquellas necesidades "disociadas del salario" (Topalov, 1979:60) son "captadas" como particulares y de los particulares. Esa superficie de la cuestión es la que veía y expresaba Macri cuando justificaba la quita de los subsidios a la energía (gas y luz) y la elevación de los

12 El empleo informal se mantuvo por encima del $30 \%$ de los trabajadores activos. 
precios a valores del mercado, porque era un "gasto que pagamos todos”. Desde ese punto de vista, el Estado es señalado como "el gran gastador" improductivo que desestimula las inversiones que no podrían existir sin la infraestructura urbana y sin fuerza de trabajo. Por su parte, librados a su suerte, los trabajadores quedan a merced de la lucha por la sobrevivencia, aumenta la pobreza, se amplía la desigualdad, la sociedad se fragmenta y empobrece y tampoco hay estímulos para las inversiones productivas necesitadas de trabajo.

Pero detrás de cada puesto de empleo y de cada unidad productiva hay personas y hogares dejados u obligados a vivir en la incertidumbre. O en el menoscabo de su valía por comparación con la figura del emprendedor triunfante o, en el lenguaje empresarial, los "unicornios"13. “...nosotros tenemos que educar a los niños y niñas del sistema educativo argentino para que hagan dos cosas: $\mathrm{O}$ sean los que crean esos empleos, que le aportan al mundo esos empleos, generan, que crean empleos... crear Marcos Galperin (por el fundador de Mercadolibre) o crear argentinos que sean capaces de vivir en la incertidumbre y disfrutarla”, señaló el ministro de Educación Esteban Bullrich, durante su disertación sobre "La Construcción del Capital Humano para el Futuro", en el Foro de Inversiones y Negocios, popularizado como Mini Davos, que tuvo lugar en el Centro Cultural Kirchner en septiembre de 2016 https://www.youtube.com/watch?v=1dvO-jorNow.

En la misma ocasión, el ministro de Ciencia y Tecnología, Lino Barañao, sostuvo que "el país debe avanzar en una economía basada en el desarrollo del conocimiento". Y agregó: "Los chicos hoy quieren crear su propia empresa, ya no sueñan tanto con ser premios Nobel” (La Nación, 15-09-2016).

El Estado de Bienestar, los derechos y las protecciones sociales fueron los modos que hallaron las sociedades para acotar la incertidumbre de las masas proletarizadas, después de haberse desestructurado el orden tradicional y haberse perdido cualquier otro medio de subsistencia. Así como “...un régimen de trabajo bajo requisitos de

13 Designa a las nuevas compañías de emprendedores que superan los US\$ 1.000 millones en valor de mercado. 
¿Qué deja el conservadurismo neoliberal?

Resquebrajamiento de los lazos sociales y algunos desafíos de la política socio-laboral

seguridad resguardados por instituciones sociales, en jornadas acotadas, con tiempos para el descanso y el esparcimiento (...) devenido en "normal" hasta en el lenguaje de los especialistas, además de ser sancionado por la ley" (Danani \& Grassi, 2009:349).

La vuelta a la incertidumbre para quienes no disponen de otro patrimonio que el de las instituciones de seguridad social (Castel, 2010), salvando las distancias de tiempo y de condiciones de su desarrollo, puede semejarse a un retorno a aquellos tiempos que Marx [(1867) 1986:219] describiera como "orgiásticos" porque se superaban todas las barreras impuestas por las costumbres y la naturaleza. Si la normalidad del trabajo se ve alterada junto con las costumbres y los modos de vida porque la mercantilización tiende a abarcar cada uno de sus espacios, y también las redes familiares tienden a ser menos extensas y más frágiles, es difícil imaginar el disfrute de la incertidumbre por parte de quienes no tengan éxito en sus empresas o no puedan crearlas, como probablemente ocurra con les niñes y jóvenes que hoy la ideología del emprendedorismo empujó a vivir en la indigencia.

\section{Salvar la sociedad, salvar la libertad}

"Mientras permanezca fiel a su tarea de crear una libertad más abundante para todos, no tendrá que temer que el poder o la planeación se vuelvan en su contra... Este es el significado de la libertad en una sociedad compleja"

Polanyi [1944] 2001:321

"La sociedad no existe". La aseveración es un aporte de Margaret Thatcher, cuando junto con Ronald Reagan representaban el triunfo del pensamiento neoliberal en el mundo desarrollado y su imposición al resto. Y si la sociedad no existe (o queda oculta tras esas contradicciones señaladas precedentemente), los problemas y las preguntas se plantean al revés: no se trata de cómo la economía satisface necesida- 
des humanas, sino de cómo se asegura la acumulación, aunque para ello esas necesidades sean insatisfechas ${ }^{14}$.

¿La economía contra la sociedad? Por cierto, la economía es el terreno ineludible, de y no contra la sociedad. La política la encauza, distribuye los beneficios y sacrificios. Los economistas y los funcionarios de las áreas económicas de los gobiernos, en lo esencial, hacen y toman decisiones políticas que atienden o desatienden intereses y necesidades sociales; que moderan las divisiones o profundizan las desigualdades. Las políticas que inspira el neoliberalismo empujan a subordinar las áreas sociales del Estado y a transformar las instituciones y cuerpos normativos en detrimento de las necesidades de reproducción de la vida de la población y de la vida social. Ponen a la economía contra la sociedad y, al desconocerla, destruyen sus tramas de interdependencia, igual que destruyen la naturaleza y ponen en peligro la vida en el planeta.

Frente a una trama social muy dañada desde hace varias décadas por el neoliberalismo, desde la dictadura pasando por los años '90, que contribuyó a profundizar el gobierno de Cambiemos con la recreación de un orden político punitivo que suma riesgos para la libertad y para las vidas; por el abandono de las poblaciones más desprovistas de protecciones a la violencia creciente del narcotráfico y del propio Estado; por el mayor deterioro de la educación pública, y también por la complejización del mundo del trabajo, ¿qué retos se presentan a una política socio-laboral que asuma la necesidad de reiniciar la reconstitución de esa trama, para contribuir a salvar a la sociedad de divisiones más profundas? Entiendo que en los tiempos que vienen, estas políticas enfrentan desafíos de distinto orden: situaciones de emergencia, cuestiones que son urgentes de encarar y otras, de tratamiento necesario, cuya problematización es incipiente.

14 Un buen ejemplo está dado por las insuficiencias y los límites de los sistemas jubilatorios vigentes, pues tal como se presenta el problema no es el bienestar de la población adulta, sino que ella misma es el problema, por lo que las soluciones conducen a afectar sus condiciones de vida. "En otras palabras, el FMI pide que la Argentina considere reducir "el tamaño de los beneficios" que recibe cada persona en su jubilación, según la propia definición del organismo multilateral. Entre sus recomendaciones más generales están extender la edad jubilatoria, reformar el sistema previsional para que haya más participación del ahorro privado y repensar las leyes laborales para la inclusión de los trabajadores de edad más avanzada, entre otras” (La Nación, 31-01-2019). 
¿Qué deja el conservadurismo neoliberal?

Resquebrajamiento de los lazos sociales y algunos desafíos de la política socio-laboral

Las primeras son demandas reiteradas que están en primer lugar de la agenda pública; las cuestiones urgentes requieren recursos y consensos fuertes; y las terceras refieren a problemas que deben encararse y necesitan de mucho debate y participación para ganarle de mano a las propuestas neoliberales: son las que tienen que ver con el trabajo.

\section{La emergencia}

Para empezar, la emergencia alimentaria. Comer es primero se titula un libro de los años '70 (Moore y Collins, 1979). Asegurar la alimentación es impostergable y no se necesitan muchos argumentos cuando hay más de un millón de niñes de entre 0 y 14 años que no satisfacen "un umbral mínimo de necesidades energéticas y proteicas". Esa es la "línea de indigencia" según define y mide el INDEC (2019:10-a). Atender esta emergencia es de primer orden y exige decisión política y, desde ya, una gestión eficiente para alcanzar a las poblaciones más distantes a lo largo del todo el territorio.

Las nuevas autoridades que asumirán el 10 de diciembre de este año 2019 tomaron pronta nota del problema y llegarán al gobierno con un Plan Nacional contra el Hambre, presentado públicamente el 6 de octubre, en la Facultad de Agronomía de la Universidad de Buenos Aires. Coordinado por Daniel Arroyo, el plan apunta a bajar los precios de la canasta básica y prevé la entrega de una tarjeta alimentaria destinada a madres de niñes menores de 6 años, entre otras medidas. En la búsqueda de consenso con un programa que involucra intereses de diversos sectores productores y distribuidores de alimentos, adelantó también la conformación de un muy amplio, por su número y composición, Consejo Federal Argentino contra el Hambre, reunido por primera vez el 15 de noviembre (La Nación, 16-11-2019; Página/12, 16-11-2019).

También es inmediatamente necesario atender la situación de quienes carecen de un lugar de habitación. El problema de la vivienda va más allá de esta emergencia, pero mientras se define una política al respecto, para muchas familias, niñes y personas adultas que están 
desamparadas, abrigarse, como comer, es primero y la calle no es un lugar de habitación y abrigo.

\section{La urgencia}

Respecto de las urgencias, cada uno de los sectores de política social presenta deficiencias que necesitan ser encaradas con premura: la vivienda, la salud, los ingresos jubilatorios, los cuidados de personas mayores o enfermas, entre otros.

Pero hay una cuestión que atañe a las generaciones jóvenes cuyas condiciones de vida las ponen en riesgo porque los servicios y los espacios de cuidado, de formación, educación, culturales y de sociabilidad son escasos y están desigualmente distribuidos. Se trata de los recursos que, más allá del trabajo, hacen a la participación en la vida social y desde donde vislumbrar proyectos de vida alternativos, experiencias diversas y donde reconocerse y ser reconocidos como partícipes valiosos de la sociedad, construyendo lazos e intercambios más allá del barrio o el territorio de habitación.

Se trata de los y las jóvenes y niñes que viven en condiciones de pobreza también porque no tienen acceso a servicios educativos, culturales, deportivos, etc. que complementan y amplían la educación escolar y a los que normalmente acceden las/los niñes de sectores medios y altos, sea a través del mercado o porque existe una oferta pública o comunitaria disponible y cercana (ODSA, 2019-a).

Existe una Ley de Protección Integral de los Derechos de las Niñas, Niños y Adolescentes (Ley 26.061), por lo que el Estado es responsable en primer lugar, aún frente a la resistencia, la falta de información o la incompetencia de los adultos para hacerse cargo. La cría humana necesita cuidados y protección que, en muchos casos, estos no la pueden sostener, menos si a su vez están desprovistos y portan una historia de desprotecciones. El monto de la AUH puede mejorarse para cubrir sus necesidades más básicas, pero seguiría siendo insuficiente como política de protección, sin una trama institucional, cultural y educativa que ofrezca sentido y permita visualizar 
¿Qué deja el conservadurismo neoliberal?

Resquebrajamiento de los lazos sociales y algunos desafíos de la política socio-laboral

proyectos de vida más allá de la sobrevivencia, de la localidad y de la experiencia inmediata.

Eso es lo que ofrecen los clubes, los talleres, los teatros, las escuelas de música, las orquestas juveniles que en las barriadas pobres no existen o dependen de organizaciones locales, de militantes o voluntarios, pero no cuentan con financiamiento o fueron desfinanciadas. Hay insuficiencia de jardines maternales, de escuelas y de escuelas en buen estado y bien equipadas. Se desmontaron, además, programas como Conectar Igualdad y en la región metropolitana se limitó el acceso al Parque de divulgación científica Tecnópolis, que hasta 2015 era de acceso abierto y atraía a familias de todos los sectores sociales.

El Estado es responsable y la provisión de estos servicios y bienes debe ser parte de una política social, cultural y educativa que haga accesible lugares y ofertas diversas que son, también, de cuidado, intercambio e interacción con otros. Es urgente ampliar una red institucional pública que comprenda los cuidados, la educación clásica y el desarrollo y producción cultural en sus diversos campos y expresiones, que contribuya a generar condiciones de vida más igualitarias. Instituciones sociales contrarias al punitivismo y permitan desafiar, también, a las únicas alternativas de identidad, sociabilidad y reconocimiento que ofrecen las bandas de delincuencia o los fundamentalismos religiosos a las generaciones jóvenes de los barrios pobres. Y también, para recrear el valor de la vida, la solidaridad y la empatía con otros humanos. Una red institucional de cuidados, educativa y cultural que asegure la mejor infraestructura, la mejor tecnología y los mejores profesionales, con lugares más y mejor equipados, cuanto más alejadas en el espacio social, o más abandonadas, estén las comunidades y los barrios. Universal por su extensión, pero comprensiva e inclusiva de la diversidad cultural y regional. Una diversidad de la que todos participen.

Es difícil, pero es urgente, se necesita un Estado nacional presente en todo el territorio, recursos financieros, técnicos, expertos, investigadores, generar consenso social, y asumir el riesgo de la crítica ilustrada al "control social y el disciplinamiento". Pero es urgente porque, aun en el mejor de los mundos, les niñes y jóvenes descuidados 
de hoy, carecerán de las disposiciones para participar creativamente y/o reconocer/se entre sus congéneres.

Comer y abrigarse es primero, pero no es suficiente. De hecho, parte de este imaginario fueron y son las nuevas Universidades que facilitan el acceso y la experiencia de la educación superior a nuevas camadas de jóvenes de sectores populares. Estas podrían ser núcleos de esas redes allí donde existan.

\section{Lo necesario}

Por último, es necesario un cuidadoso tratamiento de las condiciones actuales del mundo del trabajo. Se han producidos importantes cambios tecnológicos, y también culturales y de la identidad y conciencia del sujeto del trabajo. Socialmente, es un mundo fragmentado, con desigualdades de ingresos y de condiciones; el desempleo aumentó, principalmente en puestos protegidos; los más perjudicados son les jóvenes y las mujeres. Y el sector de la economía social y solidaria ocupa una cantidad importante de personas que producen cooperativamente y proveen de alimentos, principalmente, al mercado. Hay un conjunto grande que vive de changas intermitentes, actividades de subsistencia y/o limosneo (ODSA, 2019-b). Parte de ese mundo del trabajo no está alcanzado por las protecciones laborales y medianamente por la seguridad social (a través de la AUH, el monotributo o el monotributo social).

Sergio Palazzo, referente del Sindicato de Empleados Bancarios, citó recientemente a la ONU y a un informe del Citi Bank. Según esa organización internacional, "el avance tecnológico llevará al 20\% el desempleo global en el 2035 y al 40\% en el año 2050" (destacado en el original). En el mismo sentido, el informe del banco calcula que el " $57 \%$ de los puestos de trabajo de los países de la OCDE podrán ser reemplazados por la tecnología” en el mismo lapso ${ }^{15}$.

15 Sergio Palazzo. Discurso en la $5^{\circ}$ Conferencia Mundial de UNI Finanzas en Torremolinos, Málaga, España https://sindicalfederal.com.ar/2019/10/25/palazzo-futuro-del-trabajo-sindicatosfuertes-hoy-y-manana/ 
Sin duda, el desarrollo tecnológico cambia sustancialmente la necesidad de trabajo tal como éste está planteado hasta ahora, pero los modos como vaya a organizarse y la conducción y adaptación a esos cambios, dependen del orden y los acuerdos político-sociales que puedan evitar los daños que el capital, librado a su sola lógica, hace a la sociedad, como a la naturaleza.

Desde las últimas décadas del siglo pasado, cuando se discutía "el fin del trabajo" y, al mismo tiempo, las exigencias de flexibilización para mejorar la productividad, nuestro país vio aumentar la desocupación y el subempleo hasta perder aquellas condiciones de su mercado de trabajo que lo distinguían en la región -una relativa alta ocupación- para no reponerse cabalmente hasta el presente. En ese mismo tiempo, las ocupaciones precarias se tornaron el modelo ideal y se interpretaron como una respuesta al exceso de regulaciones (Grassi, 2003).

En estos últimos años, es el emprendedorismo ${ }^{16}$ la modalidad que entusiasmó al presidente Macri y al equipo que lo acompañó y que los llevó a confundir estrategias de sobrevivencia con actitud empresaria (Grassi, 2018:111). El ideal de disponer de trabajo sin hacerse cargo de trabajadores (sin relación de dependencia), se generalizó en la década de 1990, con los contratos a término, denunciados como contratos basura. La ley aprobada en 2003 restringió en parte esas alterativas, pero la contratación de monotributistas siguió siendo la estrategia más común de incorporación de empleados, incluso por el Estado.

Pero las nuevas modalidades de ocupación a través de plataformas dan cuenta de cambios culturales más profundos, entramados a las condiciones de vida urbana, a las posibilidades que brinda el desarrollo tecnológico, a las aspiraciones de trabajar sin que nadie fije los ritmos de trabajo, y en nuestro país, a la llegada de migrantes jóvenes y la falta de alternativas para estas generaciones.

En conjunto, estas transformaciones en el mundo del trabajo generan las condiciones socio-culturales en las que el desentendimiento

16 "El emprendedurismo le da glamur a la precariedad", dice Boaventura de Sousa Santos (2019). 
respecto del sujeto del trabajo halla oportunidad de anidamiento. Las ideologías neoliberales y los gobiernos que las representan, por su parte, son ciegas al riesgo que implica la desprotección para la integración de la sociedad y la coexistencia de la comunidad nacional, al profundizar las divisiones, acrecentando la violencia institucional en lugar de acompañar los cambios protegiendo a la sociedad y a las personas. El predominio del capital financiero hizo parecer que éste se reproduce a sí mismo, y la inteligencia artificial también, haciendo superfluo el trabajo humano y sobrante una masa de desempleados, convertidos y percibidos como desechos, pero a los que hay que atender y contener, por compasión o por seguridad, sin alterar la legitimidad de la pertenencia dada por la autovalía o el mérito de tener empleo.

Esa fue la "política laboral" del gobierno de Cambiemos, con el que reaparecieron inmediatamente los proyectos de reformas referidos antes que, justificados en esos cambios, se proponen descargar en individuos desguarnecidos la responsabilidad, no solamente de su reproducción, sino de la continuidad de la vida social.

Recuerda Danani (2005:42) que la noción de proletarización designa el proceso de "constitución del sujeto de las sociedades capitalistas". Un "proceso que requiere una motivación cultural que no es única ni uniforme, sino diversa en dos sentidos: porque está inscripta en las circunstancias históricas y en la trama de relaciones sociales (relaciones de clase, a las que a su vez constituye); y porque es producida por, y productora de la individualidad. Viendo así la cuestión, debemos pensar en proletarizaciones (en plural), pues cada ciclo histórico (¿y cada geografía?) da cuerpo a un "ser gente de trabajo" (...) y a las vidas que en él se viven (Danani \& Grassi, 2009:349).

Frente a aquel encantamiento con un mundo de emprendedores y al hecho cierto de la transformación del trabajo que también alcanza a nuestro país, haciéndose cada vez más evidente en el reemplazo de trabajadores por procesos automatizados; $y$ frente a una realidad del mundo del trabajo que da cuenta de modalidades de ocupación de la propia fuerza de trabajo, diferentes del asalariamiento clásico, es necesario repensar la legislación laboral y de protección para 
enfrentar a las "reformas neoliberales" y contribuir a enlazar a ese disímil mundo del trabajo, asumiendo la diversidad de intereses y condiciones.

La ocupación a través de plataformas, los contratos a término, la economía social que reconoce diversas modalidades (de las ocupaciones autónomas a las cooperativas, pasando por las distintas formas de la "informalidad"), no sólo son eso (modalidades de ocupación), sino procesos constitutivos de (otros) sujetos y vidas de trabajo. "Procesos de proletarización contemporánea" (Danani, 2005:40) que se alejan de la "normalidad" del empleo protegido y la relación de dependencia, que aseguraba un tránsito seguro y un retiro relativamente solvente de la vida activa. Si en nuestro país esto nunca se cumplió a cabalidad ni abarcó a toda la población trabajadora, sí constituyó un ideal y una referencia que marcaba una línea de base de condiciones de vida aceptables. Cabe, al respecto, una hipótesis. Como bien precisa Danani (ibid), la proletarización es "la transformación de trabajadores en fuerza de trabajo, y de esta en mercancía", pero esta sólo se cumple a cabalidad en procesos activos, cuando la disposición a "venderse" regularmente está garantizada a largo plazo. Es decir, en procesos culturales (de formación y disciplina) y de organización de la totalidad de la vida, en los que la identidad y la pertenencia están comprometidas, además de la reproducción cotidiana. De ahí se desprende el reconocimiento de distintas proletarizaciones en procesos concretos y mutables. La pregunta es, entonces, si el presente ciclo histórico (el "tercer capitalismo", en términos de Boltanski y Chiapello, 2002) no ha generado proletarizaciones destinadas a co-existir bajo el dominio del capital, en las que, incluso, el salario desaparece como tal. Sujetos de trabajo, identidades, disposiciones y motivaciones diferentes bajo ese dominio cuyo fin no se evidencia como inmediato. Esa diversidad se reúne en ese mundo del trabajo que necesita una/otra ley del Estado $^{17}$ que garantice la reproducción de la vida e, incluso, contribuya al mutuo reconocimiento como "gentes de trabajo".

17 Debates y controversias respecto de la naturaleza de estas relaciones y la desprotección, se 


\section{Como disputar el sentido común}

Estas y más intervenciones de y en el Estado, que permitan preservar la vida social, son urgentes y necesarias. Para ello, se necesita de la voluntad de un gobierno, pero más aún, de la voluntad de una ciudadanía que comprenda lo que está en juego.

El patrimonio social (la estructura institucional y normativa de protección social y los bienes públicos para la reproducción), han sido (son) puestos en cuestión y en riesgo por los neoliberalismos conservadores. Esos movimientos propugnan por abrir las compuertas de la economía y dejar hacer a los capitales, mientras cuidan de preservar las distancias sociales que distinguen a la "gente" con privilegios de quienes "necesitan ayudas". Para ello pueden contar con -y reproducir- las tradiciones más atávicas, que inspiran y legitiman políticas sociales punitivas y expulsivas, que exigen méritos extraordinarios para quienes ya portan el mérito de sobrevivir en la pobreza, mientras se preservan con naturalidad los privilegios de clase. En esas tramas de desigualdad social se sostienen las críticas deslegitimadoras del patrimonio social, que ven allí "gastos" y no condiciones necesarias para que la vida social sea posible.

Nada indica aún que el consenso con esa crítica a las políticas que pretendan abarcar e integrar (reconocer semejantes) a poblaciones desprotegidas y desprovistas de ingresos suficientes y servicios básicos haya sido resquebrajada, porque esa ideología distribuye desigualmente también la obligación de hacer méritos y la de disfrutar de privilegios. Tampoco permite sopesar el valor del patrimonio social y de las inversiones sociales (seguridad social, políticas redistributivas, de asistencia, etc.) con el extraordinario crecimiento y concentración de la riqueza, intensificado desde el último cuarto del siglo pasado, cuando el neoliberalismo se impuso como políticas de Estado, a nivel del sistema mundial (Piketty, 2014), como en nuestro país ${ }^{18}$.

encuentran en Beccaria y Maurizio (2019).

18 "En Argentina, un obrero tendría que trabajar 174 años para ganar la prima anual de un ejecutivo 
Las prestaciones y servicios sociales, educativos y culturales públicos, y los subsidios al consumo de los sectores más bajos, por el contrario, son siempre señalados como los "gastos" que deben controlarse, haciendo más rígidas las reglas para su merecimiento. Mientras, las ganancias extraordinarias con consumos básicos (como los alimentos y medicamentos) quedan fuera del campo de visión, de lo que es reconocible. Los precios que más aumentaron entre octubre de 2018 y el mismo mes de 2019, son los que corresponden a alimentos y salud (INDEC, octubre 2019-c).

Las necesidades que se satisfacen por aquellos servicios colectivos y demás prestaciones sociales, aunque percibidas como necesidades de los particulares que se benefician con ellas, son, sin embargo, necesidades de la sociedad misma que a través de esos sistemas se hace o preserva como una sociedad vivible. Este cambio de mirada es el desafío para la política en general y para que sean posibles aquellas otras reparaciones del tejido social dañado, tanto como el reconocimiento de esos nuevos procesos de proletarización al que se alude.

Horacio Verbitsky (2019) se refirió al resultado de las elecciones de octubre de este año como al "triunfo de la sensatez". Efectivamente, la mitad de los electores se expresaron en defensa propia, porque a lo largo de estos años las condiciones de vida de los sectores medios también empeoraron, al ritmo de la agudización de la pobreza y la indigencia, tal como ya fue dicho. Pero, qué porcentaje de esa mitad incluye en su defensa la defensa de estos otros, es una cuestión abierta. Están, además, quienes abiertamente eligieron la continuidad del conservadurismo neoliberal y que, abiertamente también y, contra toda evidencia, sostienen que "los planes sociales" (simplificación de las políticas de protección social) son causantes de las crisis económicas y de la falta de voluntad para trabajar. Con la misma inconsistente tozudez de los que en esta época sostienen que la tierra es plana, 
se sigue culpando a las víctimas. Así funcionan los prejuicios y el racismo a los que las evidencias en contrario no parecen conmoverlos. Pero contra esa irracionalidad habrá que trabajar y tendrá que hacerse cargo la política para salvar a la sociedad de la dislocación que ataca su urdimbre, cuando toda la vida se mercantiliza (Pcodaolanyi [1944], 1992:186). Por eso, tan necesario como hacer, se hace decir y explicar lo que está en juego en la política.

\section{Bibliografía}

AAVV. (2019). Agenda Urgente. Obtenido de http://www.agendaurgente.org/descargar/ Agenda_urgente_para_una_sociedad_de_trabajo.pdf

Ayos, E. y. (2018). La inseguridad desde abajo: postales sobre el "descontrol". Elaboraciones sobre el miedo al delito en diferentes grupos del espacio social. En E. y. Grassi, Tramas de desigualdad. Las políticas y el bienestar en disputa (págs. 391-419). Buenos Aires: Prometeo.

Beccaria, L., \& Maurizio, R. (27 de Febrero de 2019). Alquimias Económicas. Recuperado el 27 de Febrero de 2019, de https://alquimiaseconomicas.com/2019/02/27/ algunas-reflexiones-en-torno-al-empleo-en-plataformas-y-a-los-mecanismos-deproteccion/\#more-2928

Boltanski, L., \& Chiapello, E. (2002). El nuevo espíritu del capitalismo. España: Akal.

Castel, R. (2004). La inseguridad social ¿Qué es estar protegido? Buenos Aires: Manantial.

Castel, R. (2004). La metamorfósis de la cuestión social. Una crónica del salariado. Buenos Aires: Paidós.

Castel, R. (2010). El ascenso de las incertidumbres. Trabajo, protecciones, estatuto del individuo. Buenos Aires: Fondo de Cultura Económica.

Danani, C. (2005). La construcción socio-política de la relación asalariada: Obras sociales y sindicatos en la Argentina, 1960-2000. Tesis de doctorado. FCS-UBA: Mimeo.

Danani, C., \& Grassi, E. (2009). Trabajar para vivir o vivir para trabajar: esa es la cuestión. En E. Grassi, \& Danani, C., El mundo del trabajo y los caminos de la vida. Buenos Aires: Espacio Editorial.

De Sousa Santos, B. (s.f.). Pruebas Revista Arcadia. Recuperado el 29 de 10 de 2019, de https://pruebas.revistaarcadia.com/impresa/portada/articulo/ el-emprendedurismo-le-da-glamur-a-la-precariedad-boaventura-de-sousa-santos/78712

Durkheim, E. (1985). La división social del trabajo II. Barcelona: Planeta-Agostini. 
¿Qué deja el conservadurismo neoliberal?

Resquebrajamiento de los lazos sociales y algunos desafíos de la política socio-laboral

García Bossio, M. (s.f.). Nuso. Recuperado el 04 de 2019, de https://nuso.org/media/ articles/downloads/5.TC_Garcia_Bossio_280.pdf

Grassi, E. (2003). Política y problemas sociales en la sociedad neoliberal. La otra década infame (1). Buenos Aires: Espacio Editorial.

Grassi, E. (2018). Estado social y desbloqueo de la sociedad neoliberal. En E. Grassi, \& Hintze, S., Tramas de la desigualdad. Las políticas y el bienestar en disputa (págs. 57122). Buenos Aires: Prometeo.

Grassi, E. (2018). Post Scriptum Septiembre 2018. Cuesta abajo: la amputación de la “mano izquierda del Estado". En E. Grassi, \& Hintze, S., Tramas de desigualdad. Las políticas y el bienestar en disputa (págs. 39-53). Buenos Aires: Prometeo.

Grassi, E. (2018). Transformaciones del trabajo y la política social. En E. Grassi, \& Hintze, S., Tramas de la desigualdad. Las políticas y el bienestar en disputa (págs. 123190). Buenos Aires: Prometeo.

Grassi, E., \& Hintze, S. (2018). Tramas de desigualdad. Las políticas y el bienestar en disputa. Buenos Aires: Prometeo.

Hintze, S. (2018). El trabajo en cooperativas en Argentina del siglo XXI. Procesos, políticas e interpretaciones. En E. Grassi, \& Hintze, S., Tramas de la desigualdad. Las políticas y el bienestar en disputa (págs. 271-320). Buenos Aires: Prometeo.

Marx, K. (1986). El Capital. Crítica de la Economía Política. México: Fondo de Cultura Económica.

Moore Lappé, F., \& Collins, J. (1979). Comer es primero. Más allá del mito de la escasez. México: Siglo XXI.

Papalini, V., \& Echavarría, C. (2016). Los significados contrapuestos del bienestar de la felicidad al wellness. Ensambles, 35-53.

Piketty, T. (2014). El capital en el siglo XXI. Buenos Aires: FCE.

Polanyi, K. (1992). La gran transformación. Los orígenes políticos y económicos de nuestro tiempo. México: FCE.

Pulser, R. (05 de 2019). Nuso. Obtenido de https://nuso.org/articulo/ espiritualidad-capitalismo-neoliberalismo/?utm_source=email\&utm_medium=email

Sabarots, H. (2018). La inseguridad como problema público, las políticas de seguridad y la participación ciudadana. En L. (. Raggio, Antropología de las políticas sociales y culturales. Estudios sobre su implementación y perspectivas futuras. Buenos Aires: Editorial de la facultad de Filosofía y Letras.

Topaloy, C. (1979). La urbanización capitalista. México: EDICOL.

Unzué, M., \& Chávez Molina, E. (2019). Revista anfibia. Obtenido de http:// revistaanfibia.com/ensayo/todes-emprendedores/ 
Verbitsky, H. (s.f.). El Cohete a la Luna. Recuperado el 27 de 10 de 2019, de https://www. elcohetealaluna.com/el-triunfo-de-la-sensatez/

\section{Fuentes periodísticas}

Diario Clarín. (s.f.). Recuperado el 29 de 10 de 2019, de https://www.clarin.com/politica/ pampa-legisladora-macrista-trato-monos-votantes-frente_0_-M1w6DHV.html

Diario La Nación. (s.f.). Recuperado el 12 de 11 de 2019, de https://www.lanacion.com. ar/el-mundo/crisis-bolivia-asamblea-no-consigue-quorum-se-nid2305838

Diario La Nación. (s.f.). Recuperado el 16 de 11 de 2019, de https://www.lanacion.com. ar/politica/el-plan-alberto-fernandez-hambre-tarjeta-alimentos-nid2307109 12-11-2019

Diario La Nación. (s.f.). Recuperado el 03 de 09 de 2019, de https://www.lanacion.com.ar/economia/ el-gobierno-modifico-indemnizaciones-incapacidad-laboral-traves-nid2292622

Diario La Nación. (s.f.). Recuperado el 12 de 08 de 2019, de https://www.lanacion.com. $\mathrm{ar} /$ politica/mauricio-macri-vamos-revertir-eleccion-ayer-nid2276807

Diario La Nación. (s.f.). Recuperado el 31 de 01 de 2019, de https://www.lanacion.com. ar/economia/el-fmi-sugiere-argentina-reduzca-relacion-salario-nid2213277

Diario La Nación. (s.f.). Recuperado el 15 de 09 de 2016, de https://www.lanacion.com. ar/sociedad/la-educacion-busca-una-alianza-con-los-sectores-productivos-nid1937910

Diario Página 12. (s.f.). Recuperado el 16 de 11 de 2019, de https://www.pagina12.com. ar/231201-fernandez-convoco-a-la-epopeya-de-derrotar-el-hambre

Diario Perfil. (s.f.). Recuperado el 29 de 10 de 2019, de https://www.perfil.com/noticias/ actualidad/un-fiscal-de-mesa-fue-discriminado-por-su-ropa-en-las-redes-socialeselecciones-2019.phtml

Infobae. (s.f.). Recuperado el 19 de 10 de 2019, de https://www.infobae.com/ fotos/2019/10/19/las-mejores-fotos-de-la-marcha-del-millon-en-el-obelisco/

Infobae. (s.f.). Recuperado el 19 de 10 de 2019, de https://www.infobae.com/ politica/2019/10/19/macri-encabezara-la-marcha-del-millon-en-el-obelisco-con-la-queespera-forzar-un-balotaje/

Infobae. (s.f.). Recuperado el 03 de 09 de 2019, de https://www.infobae.com/sociedad/2019/09/24/ derrumbe-en-las-obras-de-ampliacion-de-ezeiza-hay-un-muerto-y-siete-heridos/

Página 12. (s.f.). Recuperado el 30 de 10 de 2019, de https://www.pagina12.com. ar/228065-para-grobocopatel-el-problema-es-que-la-gente-comun-compro-d 
¿Qué deja el conservadurismo neoliberal?

Resquebrajamiento de los lazos sociales y algunos desafíos de la política socio-laboral

Revista Noticias. (s.f.). Recuperado el 11 de 11 de 2019, de https://noticias.perfil.com/ noticias/internacionales/quien-es-el-macho-camacho-el-bolsonaro-de-bolivia.phtml

\section{Fuentes documentales}

Observatorio de la Deuda Social. (2019). Obtenido de http://wadmin.uca.edu.ar/public/ ckeditor/Observatorio\%20Deuda\%20Social/Documentos/2019/2019-OBSERVATORIODOCUMENTO-ESTADISTICO-HETEROGENEIDAD-FRAGMENTACION.pdf

Observatorio de la Deuda Social. (2019). Obtenido de http://wadmin.uca.edu.ar/ public/ckeditor/Observatorio\%20Deuda\%20Social/Documentos/2019/2019-BDSIDOCUMENTO-INVESTIGACION-POBREZA-INFANCIA-BOLETIN-1.pdf

INDEC. (2019). Obtenido de https://www.indec.gob.ar/uploads/informesdeprensa/ ipc_11_190482C4BD54.pdf

INDEC. (2019). Obtenido de https://www.indec.gob.ar/uploads/informesdeprensa/ mercado_trabajo_eph_1trim19B489ACCDF9.pdf

INDEC. (2019). Obtenido de https://www.indec.gob.ar/uploads/informesdeprensa/eph pobreza_01_19422F5FC20A.pdf

Oxfam Argentina. (s.f.). Recuperado el 18 de 11 de 2019, de https://www.

oxfamargentina.org/que-hacemos/reducimos-desigualdad/ 